\title{
Adaptive range selection by golden eagles in a changing landscape: A multiple modelling approach
}

\author{
Fabrizio Sergio $^{\mathrm{a}, *}$, Paolo Pedrini ${ }^{\mathrm{b}}$, Franco Rizzolli ${ }^{\mathrm{b}}$, Luigi Marchesi ${ }^{\mathrm{b}}$ \\ a⿳Department of Conservation Biology, Estación Biológica de Doñana, C.S.I.C., Avda. de María Luisa s/n., Pabellón del Perú, \\ Apdo 1056, 41013 Seville, Spain

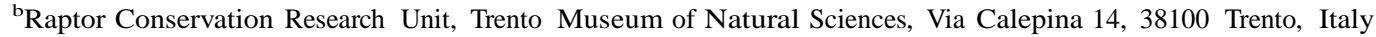

A B S T R A C T

Keywords:

Agro-pastoralism

Habitat selection

Land abandonment

Nest-site selection

Woodland expansion

\begin{abstract}
and abandonment is causing considerable woodland expansion in many mountainous areas of Europe, with potential repercussions on conservation-sensitive species typical of open habitats. We examined the potential impact of such changes on an alpine golden eagle population, by estimating the ranges potentially used by the eagles for foraging through different techniques (concentric circles of different radii and a tessellationmethod based on telemetry data). Compared to randomly located territories, eagles selected ranges farther away from conspecifics, characterised by a rugged topography and rich in main prey species and in open habitats favoured by their main prey species, such as grassland, shrubs, xerophytic vegetation and rocky outcrops. Similarly, nest spacing and breeding success were related to the availability of optimal foraging habitats, also favoured by the main prey species of the eagles. Even though woodland-variables did not enter any of the stepwise models, eagles were dependent on grassland habitats, currently lost to woodland at a rate of about $0.5-1 \%$ per year, and on shrub vegetation rapidly evolving into woodland, which accounted on average for almost $10 \%$ of the eagle ranges. Longterm loss of such habitat may imply up to a $66 \%$ woodland increase for some eagle ranges. Given the complexity of the uncovered relationships and difficulty to make firm predictions, subsidies to halt the abandonment of traditional agro-pastoral practices seem urgently needed.
\end{abstract}

(C) 2006 Elsevier Ltd. All rights reserved.

\section{Introduction}

Socio-economic changes can be powerful determinants of landscape structure and composition, with important repercussions on local biotas (Forman, 1995; Pain and Pienkowski, 1997; Hunter, 1999; Hutchings et al., 2000). In many mountainous areas of Europe, the declining profitability of agro-pastoral activities is causing widespread land abandonment, with consequent woodland expansion into previously cultivated areas (Cernusca et al., 1999) and negative impacts on species of open habitats (e.g., Tucker and Evans, 1997; Penteriani et al., 2002; Laiolo et al., 2004). In line with such continentwide trends, in the Alps woodland extent is increasing through natural regeneration by $0.5-1 \%$ per year, almost exclusively at the expense of abandoned pastures (e.g., PAT, 1995; Barbaro et al., 2001; CIPRA, 2001; Dirnböck et al., 2003), one of the most threatened of European habitats (e.g., Niemelä and Baur, 1998; Canals and Sebastià, 2000 and references therein). This change can be separated into two simultaneous processes: (1) at medium-low elevations, land abandonment causes the loss of grassland fields originally managed for fodder production in association with the once

\footnotetext{
* Corresponding author: Tel.: +39 461816089.

E-mail address: fsergio@ebd.csic.es(F. Sergio). 0006-3207/\$ - see front matter (c) 2006 Elsevier Ltd. All rights reserved. doi:10.1016/j.biocon.2006.05.015
} 
flourishing livestock industry, an agro-pastoral system which dates back to 6000 years ago (Lichtenbergen, 1994; Dirnböck et al., 2003); (2) at higher elevations, the rapidly declining utilization of alpine pastures for livestock rearing is causing an upward shift of the tree line, originally lowered by human action in order to increase the surface available for grazing (Dirnböck et al., 2003). The latter trend may be exaggerated by climate warming (Holtmeier, 1994). Both processes promote a temporary increase in shrub vegetation, which ultimately develops into woodland, leading to long-term loss of alpine grassland and pastures, and a decline in landscape heterogeneity. Such large-scale changes call for an urgent need to assess their potential impact on conservation-sensitive species typical of open habitats, such as the golden eagle Aquila chrysaetos.

The golden eagle is a large, territorial raptor which captures most of its prey in open habitats with short or sparse vegetation (McGrady, 1997; Watson, 1997). In Europe it has an unfavourable conservation status, with population declines reported for various countries (Watson, 1994; Haller and Sackl, 1997). It is a good model species to investigate the impact of landscape changes because (1) it has been repeatedly demonstrated to be sensitive to afforestation and loss of open habitats (Marquiss et al., 1985; Watson, 1992; Whitfield et al., 2001); (2) it is a wide ranging species, difficult to preserve through site-protection, and better managed through conservation plans that integrate protection of the environment with other land-uses (Watson, 1991; Watson and Whitfield, 2002; Sergio et al., 2005a); and (3) it is included in the Annex 1 of the European Union Directive on the Conservation of Wild Birds (79/409/ECC), which must be implemented by member states, and which requires investigation of habitat requirements and conservation of habitat features insuring survival and reproduction of the listed species (e.g., Watson and Whitfield, 2002).

In the Alps, the golden eagle is a year-round resident species. The bulk of the population is concentrated in the inner portion of the Alps, with lower densities in the outer, prealpine periphery of the mountain chain (Pedrini and Sergio, 2002). The diet is dominated by carrion of large mammals in winter and by alpine marmot Marmota marmota, alpine chamois Rupicapra rupicapra, roe deer Capreolus capreolus, mountain hare Lepus timidus and black grouse Tetrao tetrix during the breeding season, most of them captured in open habitats such as grassland, rocky outcrops or sparse shrubs (Haller, 1996; Pedrini and Sergio, 2002). Apart from a coarse analysis of nest spacing in relation to woodland expansion (Pedrini and Sergio, 2001a), few data on golden eagle habitat selection are available for the Alps (Jenny, 1992; Haller, 1996). Here, we report a comprehensive analysis of the environmental factors affecting nest-site selection, territory spacing and breeding success for a population located in the central-eastern portion of the Italian Alps.

\section{Study area}

Golden eagles were surveyed within the Trento region, a $6200 \mathrm{~km}^{2}$ area in the central-eastern Italian Alps and pre-Alps $\left(45^{\circ} \mathrm{N}, 11^{\circ} \mathrm{E}\right)$. Elevation of the study area ranged from 65 to $3764 \mathrm{~m}$ a.s.l. Thirty-one percent of the land lay below
$1000 \mathrm{~m}$; these areas are rarely used by golden eagles for hunting. Twenty-eight percent of the area lay at an elevation between 1000 and $1500 \mathrm{~m}, 22 \%$ between 1500 and $2000 \mathrm{~m}, 13 \%$ between 2000 and $2500 \mathrm{~m}$, and 6\% at an elevation $>2500 \mathrm{~m}$. The natural tree line was at 1800-1900 m, but had often been lowered by human activities and sheep grazing (Piussi, 1992). The landscape was characterised by cultivated valley floors, mountain slopes covered by forests interspersed with sparse pastures, and by montane grassland, rocky outcrops and permanently snow-covered ground above the tree line. Fifty-two percent of the area was covered by woodland, $18 \%$ by montane grassland and pastures, $6 \%$ by agricultural crops (mainly vineyards and apple groves) and $3 \%$ by human development. Forest composition varied from deciduous to coniferous depending on elevation, slope orientation, and local microclimate. With increasing elevation, woodland tended to correspond to the following forest types: Quercus pubescens, Quercus-Tilia-Acer spp., Fagus-Abies spp., Picea spp. and Larix spp.-Pinus cembra (PAT, 1995). Eighty-two percent of the woodland area was managed for wood production; $73 \%$ of this woodland was managed as mature forest and $27 \%$ by coppice (PAT, 1995). Woodland extent is currently increasing at a rate of $1.9 \%$ every three years, mainly at the expense of Alpine and sub-Alpine grassland (PAT, 1995).

\section{Methods \\ 3.1. Field procedures}

The local golden eagle population was censused annually from 1982 to 1992 inclusive, by watching transfers of nest materials and territorial and courtship displays in the two months preceding egg-laying (details in Pedrini and Sergio, 2001b). Nests were checked when nestlings were at least 51 days old to estimate the number of fledged young (nestlings usually fledge at 70-80 days old, Watson, 1997). For each territory, breeding success was expressed as the percentage of checked nesting attempts which were successful (i.e., at least one chick raised to fledging age). Only territories where productivity had been checked for at least three years were included in the analyses.

\subsection{Statistical and GIS analyses}

Data were available for 43 golden eagle territories. Of these, we used 33 for model building and 10 for model validation (Fielding and Bell, 1997). We employed logistic regression (Tabachnick and Fidell, 1996) with a backward stepwise procedure to analyse the environmental and biotic factors (Table 1) discriminating between the 33 eagle territories (i.e., one randomly chosen nest used within each territory) and 33 random locations. All random locations were generated by means of the extension "Animal Movement" of the GIS software ArcView 3.2 (Hooge and Eichenlaub, 1997). Because golden eagles in our area nest almost exclusively on cliffs at least $50 \mathrm{~m}$ high (see Section 4), random locations were only plotted on cliffs P50 $\mathrm{m}$ in height. All such cliffs were also visited in the field and only retained as random locations if judged as potentially, structurally suitable for nesting, based on familiarity with the species in the region (i.e., cliffs with plenty of large 
Nest area-level

Aspect (degrees)

Elevation (m)

Cliff height $(\mathrm{m})$

Length of cliff complex (m)

$\%$ slope

Micro-ruggedness index

Distance variables

NND (m)

Distance to open (m)

Distance to path (m)

Distance to dirt road (m)

Distance to road (m)

Distance to building (m)

Distance to village (m)

Landscape-level

Macro-ruggedness index

Mean elevation (m)

Calcareous

Thiessen-range size $\left(\mathrm{km}^{2}\right)$

$\%$ alpine grassland

$\%$ grassland fields

$\%$ arid-rocky

$\%$ mosaic

$\%$ shrubs in evolution

$\%$ shrubs

$\%$ water

$\%$ farmland

$\%$ urban areas

$\%$ broadleaved woodland

$\%$ conifer woodland

$\%$ mixed woodland

$\%$ high forest

$\%$ coppice

$\%$ open areas

$\%$ total grassland

$\%$ total shrubs

$\%$ woodland

Habitat diversity

Interspersion index

Woodland-open interspersion

Grassland interspersion index

Alpine marmot

Alpine chamois

Roe deer

Mountain hare

Black grouse

Main prey availability
Characteristics of the nest and its immediate surroundings

Orientation of the nest-site, expressed as deviation from the North

Elevation of the nest a.s.l.

Height of the cliff above the ground in the nesting portion of the cliff

Length of the cliff complex

$\%$ slope within $100 \mathrm{~m}$ of the nest

Number of 10-m contour lines crossed by two N-S and W-E transects of $200 \mathrm{~m}$

Distance to conspecifics and sources of human disturbance

Distance to the nearest conspecific

Distance to the nearest area of open habitat

Distance to the nearest path

Distance to the nearest dirt road

Distance to nearest paved road

Distance to the nearest inhabited building

Distance to the nearest village or town

Landscape structure and composition within various radii of the nest ${ }^{\mathrm{a}}$

Number of contour lines crossed by two N-S and W-E transects

Mean elevation (calculated by GIS with a $10 \mathrm{~m}$-resolution digital elevation model)

Dummy variable: soil mostly calcareous (1) or not (2)

Area of the Thiessen-range (only measured for the Thiessen-range)

$\%$ extent of alpine grassland (above the tree line)

$\%$ extent of grassland (includes both actively managed and abandoned fields)

$\%$ extent of rocky outcrops and xerophytic vegetation

$\%$ extent of mosaic, shrub vegetation along the tree line

$\%$ extent of shrubs evolving into woodland vegetation after land abandonment

$\%$ extent of shrub vegetation

$\%$ extent of water bodies

$\%$ extent of intensively managed farmland (mainly apple groves and vineyards)

$\%$ extent of urban areas

$\%$ extent of broadleaved woodland

$\%$ extent of coniferous woodland

$\%$ extent of mixed coniferous-broadleaved woodland

$\%$ of woodland area covered by mature forests

$\%$ of woodland area covered by coppice forests

$\%$ extent of open habitats (includes all grassland, arid-rocky and shrub vegetation)

Sum of \% alpine grassland and \% grassland fields

Sum of \% mosaic, \% shrubs in evolution and \% shrubs

$\%$ extent of total woodland (broadleaved + coniferous + mixed)

Shannon index ${ }^{c}$ of habitat diversity (Krebs, 1998)

Number of habitat edges ${ }^{b}$

Number of edges between woodland and open habitats ${ }^{b}$

Number of edges between grassland and other habitats ${ }^{b}$

$\%$ of $1-\mathrm{km}^{2}$ quadrats occupied by Alpine Marmots

$\%$ of $1-\mathrm{km}^{2}$ quadrats occupied by Alpine Chamois

$\%$ of $1-\mathrm{km}^{2}$ quadrats occupied by Roe Deers

$\%$ of $1-\mathrm{km}^{2}$ quadrats occupied by Mountain Hares

$\%$ of $1-\mathrm{km}^{2}$ quadrats occupied by Black Grouse

Mean of the previous five variables

a Measured within the $3 \mathrm{~km}$ "core-range", the $4 \mathrm{~km}$ "NND-range" and the "Ihiessen-range" (see Section 3 ).

b Number of edges calculated along two N-S and W-E transects, with a length equal to the one of the circle diameter, and crossing each other over the nest or random location.

c Calculated as $\left(\log _{e} \mathrm{p}\right)$, where $\mathrm{p}$ is the proportion of each land-cover type.

enough crevices or ledges protected by overhangs). In addition, because the eagles are territorial and solitary nesters with a regular dispersion of nest-sites (Haller, 1996; Watson, 1997; Pedrini and Sergio, 2001b), the minimum nearest neighbour distance (NND) among random locations was set to be the same as the minimum NND among eagle territories (see Sergio et al., 2004b, for a similar procedure). Finally, random locations were plotted within the same range of elevation of the eagle nests, so as to avoid plotting them in unsuitable locations (e.g., because of extreme climate at high elevations). The variables of Table 1 were measured in the field, or derived from digitised land-use maps (CEC, 1993; Servizio Foreste, 1999) and aerial colour-photographs (1 m resolution, courtesy of Provincia Autonoma di Trento, "Permit IGM n.278 of 30 June 2000") and were chosen so as to measure: (1) the structural characteristics of the nest-site and its immediate 
surroundings (within a radius of $100 \mathrm{~m}$ ), (2) the distance to potential hunting grounds or to sources of human disturbance, and (3) the structure and composition of the landscape, and the availability of main prey species within 3 and $4 \mathrm{~km}$ of the nest. The measure of $3 \mathrm{~km}$ was chosen because, based on telemetry data, a circle with this radius has been shown to represent a good approximation of the core home range of golden eagles (Steenhof et al., 1983; Kochert et al., 1999; McGrady et al., 2002). The measure of $4 \mathrm{~km}$ was chosen because it was approximately half the mean NND in our population (Pedrini and Sergio, 2001b, see Watson, 1992 for a similar procedure), and based on the following observations: (1) golden eagles generally occupy exclusive and regularly spaced ranges; (2) mean foraging range size in the Swiss Alps for territorial adults was quantitatively estimated at $41.8 \mathrm{~km}^{2}$ in 1980-1981 (Haller, 1982), corresponding to a circle of 3.6-km radius, which was exactly half the mean NND of the local population in that period (Haller, 1996); and (3) $4 \mathrm{~km}$ was the mean distance between the nest and kill sites in a telemetry study (Marzluff et al., 1997).

Recently, McGrady et al. (2002) have proposed an alternative procedure to model golden eagle selection of a territorial range (RIN model, for subsequent model applications see Whitfield et al., 2001; McLeod et al., 2002a,b). Based on comparison with the range configurations measured by telemetry, they showed that, if the local distribution of nest-sites is known, the best approximation of an eagle range is calculated through the following procedure: (1) identify the range centre, calculated as the mean location of the alternative nests of a pair, weighed by their use; (2) for territories with NND $<12 \mathrm{~km}$, draw up straight range boundaries at equidistant points between range centres; (3) for territories with NND $>12 \mathrm{~km}$, draw up range boundaries as the circumference of a circle of $6 \mathrm{~km}$ radius; (4) based on the above, connect boundary lines so as to draw Thiessen polygons around each range centre; (5) delete from such polygons areas at elevations not used by the eagles (details of the overall procedure in McGrady et al., 2002). In our population, eagles rarely use areas within $200 \mathrm{~m}$ of elevation above the valley floors, probably because of excessive human presence and intensive cultivation. Such cut-off point was altered for some territories and random locations depending on local topography, extent of cultivation, and availability of standardized observations of foraging eagles (unpublished data). Because the so-calculated Thiessen polygons vary in size among ranges, two territories could show similar percentages but different absolute areas occupied by a single land-cover type. For this reason, we built the logistic model twice using both the percentages and the actual areas of each land-cover type. However, because the results were exactly the same, for simplicity we only present the model based on percentages, so as to conform to previous analyses (Whitfield et al., 2001; McLeod et al., 2002a,b).

Hereafter, we refer to the $3 \mathrm{~km}$-circle as the "core-range", to the $4 \mathrm{~km}$-circle as the "half-NND-range" and to the RIN model of McGrady et al. (2002) as the "Thiessen-range”. Because each of the above three range-estimates may weigh different habitat-components potentially important for golden eagles, we conducted a different logistic model for each one. To compare the strength of the different models we (1) re-applied each one to the dataset used to build it; (2) validated them on an independent sample of 10 eagle territories and 10 random locations not used for model building; and (3) fitted the variables which entered the three alternative logistic models to an overall stepwise logistic model to check which were the best overall predictors of range occupancy. Finally, to gain an understanding of habitat relationships at a larger spatial scale, we conducted a logistic regression discriminating between 25 quadrats of $100 \mathrm{~km}^{2}$ occupied by at least one eagle territory and 25 quadrats without eagle territories.

Prey availability (Tables 1 and 2) was estimated from the GIS database of the "Archivio Dipartimento Foreste e Montagna" of the Autonomous Province of Trento. The database stores information on the presence-absence of 16 species in 1-km² sample quadrats, based on censuses mainly carried out in 1997. We used data for the five main prey species of the local golden eagle population (Pedrini and Sergio, 2001b): alpine marmot, alpine chamois, roe deer, mountain hare and black grouse. For each eagle range, we estimated prey abundance as (1) the percentage of $1-\mathrm{km}^{2}$ quadrats included in the range and occupied by each of the five prey species; and (2) as the previous variable averaged across the five prey species (Table 1). We assumed that the well-demonstrated correlation between species distribution and local abundance (Hanski, 1999; Brown, 1984) made the differences in distribution a reliable indicator of underlying differences in abundance.

To reduce collinearity and the number of variables presented to the logistic models, we employed the method of variable reduction proposed by Green (1979) and commonly employed in habitat selection studies (e.g., Austin et al., 1996; Sergio and Bogliani, 2000 and references therein). In this method, pairs of strongly intercorrelated, explanatory variables $(r>0.6)$ are considered as estimates of one underlying factor. Only one of the two is retained for analysis, usually the one likely to be perceived as more important by the study organism. Of the remaining variables, only those for which significant univariate differences $(p<0.1)$ were detected among nests and random locations were included in multivariate analyses.

To gain a deeper understanding of eagle habitat quality and to test whether the observed habitat choices were adaptive (Sergio et al., 2003a,b), we used multiple regression (Sokal and Rohlf, 1981) to relate NND and breeding success to the variables which entered the previous habitat selection models, and to all variables that were related $(r>0.4)$ to breeding success in univariate correlations.

To investigate the environmental variables related to high prey availability, we conducted a multiple regression with "Main prey availability" (see Table 1) as the dependent variable. The explanatory variables fitted to the model included all those that were related $(r>0.4)$ to Main prey availability in univariate correlations. Collinearity was reduced by employing only one of two strongly intercorrelated variables ( $\mathrm{r}>0.6)$.

In all analyses, logistic and multiple regression models were run through a generalized linear model procedure (GLM, software GLIM 4), following Crawley (1993): all explanatory variables were fitted to the model, extracted one at a time from such maximal model and the associated change in model deviance assessed by an F-test for multiple regression (GLM model with normal errors and an identity link function) 
Table 2 - Environmental variables measured at 33 golden eagle nests and at 33 random locations (Trento region, Italian Alps)

\begin{tabular}{|c|c|c|}
\hline Variable & Nest-sites & Random locations \\
\hline \multicolumn{3}{|l|}{ Nest area-level } \\
\hline Aspect $^{\mathrm{a}}$ & $238.1 \pm 79.8$ & $238.3 \pm 69.5$ \\
\hline Elevation $^{\mathrm{b} *}$ & $1643.9 \pm 49.6$ & $1650.9 \pm 74.5$ \\
\hline Cliff height ${ }^{c}$ & $106.4 \pm 11.8$ & $85.2 \pm 8.4$ \\
\hline Length of cliff complex & $347.3 \pm 62.4$ & $248.0 \pm 33.4$ \\
\hline$\%$ slope $^{\mathrm{b}}$ & $117.2 \pm 5.4$ & $119.1 \pm 5.7$ \\
\hline Micro-ruggedness index ${ }^{c}$ & $33.0 \pm 1.3$ & $32.9 \pm 1.7$ \\
\hline \multicolumn{3}{|l|}{ Distance variables } \\
\hline $\mathrm{NND}^{\mathrm{b} *}$ & $8088.3 \pm 391.8$ & $6246.2 \pm 251.7$ \\
\hline Distance to open ${ }^{c}$ & $522.1 \pm 55.0$ & $413.8 \pm 69.1$ \\
\hline Distance to path ${ }^{c}$ & $330.2 \pm 32.7$ & $273.6 \pm 35.6$ \\
\hline Distance to dirt road ${ }^{\mathrm{c}}$ & $635.2 \pm 58.5$ & $774.3 \pm 86.2$ \\
\hline Distance to road ${ }^{\mathrm{b}}$ & $1845.0 \pm 233.4$ & $1941.9 \pm 188.3$ \\
\hline Distance to building $^{c}$ & $1132.4 \pm 89.0$ & $1155.2 \pm 96.9$ \\
\hline Distance to village $^{\mathrm{b}}$ & $3050.2 \pm 323.6$ & $2598.1 \pm 253.9$ \\
\hline \multicolumn{3}{|l|}{ Landscape-level } \\
\hline Macro-ruggedness index ${ }^{\mathrm{c}, \mathrm{d}}$ & $971.7 \pm 30.2$ & $931.2 \pm 38.5$ \\
\hline Mean elevation** & $1716.8 \pm 65.9$ & $1459.9 \pm 69.2$ \\
\hline Calcareous $^{\mathrm{e}}$ & 77.8 & 81.8 \\
\hline Thiessen-range size** & $55.8 \pm 0.8$ & $47.7 \pm 1.5$ \\
\hline$\%$ alpine grassland $^{\mathrm{f}}$ & $5.7 \pm 0.9$ & $2.9 \pm 0.6$ \\
\hline$\%$ grassland fields $^{\mathrm{f}}$ & $3.4 \pm 0.9$ & $2.7 \pm 0.8$ \\
\hline$\%$ arid-rocky ${ }^{\mathrm{f}_{* *}}$ & $15.8 \pm 2.9$ & $2.7 \pm 0.6$ \\
\hline$\%$ mosaic $^{f}$ & $3.1 \pm 0.5$ & $2.6 \pm 0.4$ \\
\hline$\%$ shrubs in evolution ${ }^{\mathrm{f}_{*}}$ & $9.1 \pm 1.0$ & $5.4 \pm 1.2$ \\
\hline$\%$ shrubs $^{\mathrm{f}}$ & $2.8 \pm 0.5$ & $3.0 \pm 0.6$ \\
\hline$\%$ water $^{\mathrm{f}}$ & $0.06 \pm 0.04$ & $0.07 \pm 0.04$ \\
\hline$\%$ farmland $^{\mathrm{f}}$ & $1.3 \pm 0.3$ & $0.9 \pm 0.3$ \\
\hline$\%$ urban areas ${ }^{\mathrm{f}_{*}}$ & $2.3 \pm 0.1$ & $0.0 \pm 0.0$ \\
\hline$\%$ broadleaved high forest $^{\mathrm{f}}$ & $0.2 \pm 0.1$ & $0.3 \pm 0.1$ \\
\hline$\%$ conifer high forest ${ }^{\mathrm{f}}$ & $14.9 \pm 1.6$ & $18.1 \pm 2.1$ \\
\hline$\%$ mixed high forest ${ }^{\mathrm{f}}$ & $22.7 \pm 1.8$ & $27.0 \pm 2.2$ \\
\hline$\%$ high forest ${ }^{\mathrm{f}}$ & $37.9 \pm 3.2$ & $45.4 \pm 3.6$ \\
\hline$\%$ coppice $^{\mathrm{f}}$ & $6.7 \pm 2.1$ & $4.4 \pm 1.2$ \\
\hline$\%$ open areas ${ }^{\mathrm{f}_{*}}$ & $41.8 \pm 4.0$ & $24.5 \pm 2.3$ \\
\hline$\%$ total grassland ${ }^{\mathrm{f}+}$ & $14.0 \pm 1.4$ & $8.4 \pm 1.1$ \\
\hline$\%$ total shrubs ${ }^{f}$ & $15.1 \pm 1.5$ & $11.0 \pm 1.1$ \\
\hline$\%$ woodland $^{\mathrm{f}}$ & $44.6 \pm 2.9$ & $49.8 \pm 3.4$ \\
\hline Habitat diversity & $0.17 \pm 0.01$ & $0.17 \pm 0.02$ \\
\hline Interspersion index ${ }^{\mathrm{c}, \mathrm{d}}$ & $57.6 \pm 2.7$ & $57.8 \pm 2.0$ \\
\hline Woodland-open interspersion ${ }^{\mathrm{c}, \mathrm{d}}$ & $40.7 \pm 2.6$ & $38.6 \pm 2.0$ \\
\hline grassland interspersion index ${ }^{\mathrm{c}, \mathrm{d}}$ & $33.7 \pm 3.2$ & $36.9 \pm 2.6$ \\
\hline Alpine marmot $\mathrm{f}_{* *}$ & $23.5 \pm 3.1$ & $13.6 \pm 3.0$ \\
\hline Alpine chamois ${ }^{f}$ & $72.9 \pm 2.9$ & $78.3 \pm 4.0$ \\
\hline Roe deer $^{\mathrm{f}_{* *}}$ & $86.7 \pm 2.8$ & $54.3 \pm 5.6$ \\
\hline Mountain hare $\mathrm{f}_{* *}$ & $58.6 \pm 5.4$ & $13.6 \pm 3.0$ \\
\hline Black grouse $\mathrm{f}_{* *}$ & $48.9 \pm 2.6$ & $18.9 \pm 3.7$ \\
\hline Main prey availability ${ }^{\mathrm{f}_{* *}}$ & $58.1 \pm 1.8$ & $35.7 \pm 2.8$ \\
\hline
\end{tabular}

Univariate differences between the two samples were tested by means of t-tests. ${ }^{+} 0.05<\mathrm{P}<0.1$; ${ }^{*} \mathrm{P}<0.05$; ${ }^{* *} \mathrm{P}<0.01$; ${ }^{* * *} \mathrm{P}<0.001$. For simplicity of presentation, landscape-level variables are only shown for the Thiessen-ranges mean values for core-ranges and NND-ranges are available on request from the corresponding author.

a Measured in degrees and as deviation from the North. The mean is given \pm 1 angular deviation. Difference tested by mean of the WatsonWilliams test for two samples (Zar, 1984).

b t test carried out on the variable $\log _{e}$ transformed.

c $t$ test carried out on the variable square-root transformed.

d Measured for the half-NND-circle.

e \% of cases in which the soil is mainly calcareous. Difference tested by means of a $v^{2}$ test on the count data.

$\mathrm{f} t$ test carried out on the variable transformed in the arcsin square-root of the proportion. 
or $\mathrm{a} \mathrm{v}^{2}$ test for logistic regression (GLM model with binomial errors and a logit link function). In all analyses, each eagle territory is used only once to avoid pseudoreplication, means are given $\pm 1 \mathrm{SE}$, tests are two-tailed, and statistical significance was set at a 60.05 . When multiple tests were performed on the same data set, the sequential Bonferroni correction was used to adjust the significance level (Rice, 1989). Throughout the paper, the terms territory and range are used interchangeably (Whitfield et al., 2001).

\section{Results}

\subsection{Nest-site and range selection: core-range}

Two variables had access to the stepwise logistic regression discriminating between eagle nests and random sites: NND and Main prey availability (Table 3a). Therefore, compared to random sites, eagle ranges were farther apart and had higher availability of main prey species.

\subsection{Nest-site and range selection: half-NND-range}

Three variables entered the stepwise logistic regression discriminating between eagle nests and random sites: NND, \% total grassland and \% arid-rocky (Table 3b). Compared to random sites, eagle ranges had higher NNDs and higher availability of grassland and xerophytic habitats.

\subsection{Nest-site and range selection: Thiessen-range}

Three variables entered the stepwise logistic regression discriminating between eagle nests and random sites: NND, \% shrubs in evolution and Main prey availability (Table 3c). Compared to random sites, eagle ranges had higher nest spacing, higher availability of shrub vegetation evolving into woodland, and higher availability of main prey species.

\subsection{Comparison among the three models}

The model based on the Thiessen-range performed consistently better than the other models, both when re-applied to the dataset used to build it and when validated on the independent dataset (Table 4). When all the variables which entered the previous models were fitted altogether to a logistic model, the output model replicated the one of the Thiessen-range, incorporating NND, \% shrubs in evolution and Main prey availability.

\subsection{Range selection: $100-\mathrm{km}^{2}$ quadrats}

Two variables had access to the stepwise logistic model discriminating between 25 quadrats occupied by Golden eagles and 25 non-occupied quadrats: macro-ruggedness and \% farmland (Table 3d). Compared to non-occupied ones, eaglequadrats had a more complex topography and lower availability of intensively cultivated areas.

Table 3 - Logistic regression models (GLM with binomial errors and a logit link function) that best separated 33 golden eagle territories from 33 random locations (models a, b, c) and 25 quadrats of $100 \mathrm{~km}^{2}$ occupied by golden eagle territories from 25 quadrats not occupied by golden eagles (model d) (Trento region, central-eastern Italian Alps)

\begin{tabular}{|c|c|c|c|}
\hline Variable & $\mathrm{B}$ & $\mathrm{t}$ & $\mathrm{p}$ \\
\hline \multicolumn{4}{|l|}{ a. Core-range } \\
\hline $\mathrm{NND}^{\mathrm{a}}$ & $2.64 \pm 0.95$ & 2.79 & $<0.04$ \\
\hline Main prey species ${ }^{\mathrm{b}}$ & $6.05 \pm 2.23$ & 2.71 & $<0.04$ \\
\hline Constant & $-27.78 \pm 8.90$ & - & - \\
\hline \multicolumn{4}{|l|}{ b. Half-NND-range } \\
\hline $\mathrm{NND}^{\mathrm{a}}$ & $2.98 \pm 0.99$ & 3.00 & $<0.03$ \\
\hline$\%$ total grassland ${ }^{\mathrm{b}}$ & $5.16 \pm 2.32$ & 2.22 & $<0.05$ \\
\hline$\%$ arid-rocky ${ }^{\mathrm{b}}$ & $2.97 \pm 1.45$ & 2.05 & $<0.05$ \\
\hline Constant & $-28.8 \pm 9.11$ & - & - \\
\hline \multicolumn{4}{|l|}{ c. Thiessen-range } \\
\hline $\mathrm{NND}^{\mathrm{a}}$ & $6.69 \pm 2.70$ & 2.48 & $<0.02$ \\
\hline$\%$ shrubs in evolution ${ }^{\mathrm{b}}$ & $27.40 \pm 9.39$ & 2.92 & $<0.02$ \\
\hline Main prey species ${ }^{b}$ & $29.39 \pm 9.83$ & 2.99 & $<0.03$ \\
\hline Constant & $-88.10 \pm 32.06$ & - & - \\
\hline \multicolumn{4}{|l|}{ d. $100-\mathrm{km}^{2}$ quadrats } \\
\hline Macro-ruggedness index ${ }^{c}$ & $1.15 \pm 0.54$ & 2.12 & $<0.05$ \\
\hline$\%$ farmland & $-5.04 \pm 2.27$ & 2.22 & $<0.05$ \\
\hline Constant & $-8.01 \pm 4.53$ & - & - \\
\hline
\end{tabular}

Landscape variables were measured for the core-range (circle of $3 \mathrm{~km}$ radius) in model a, for the half-NND-range(circle of $4 \mathrm{~km}$ radius) in model b, and for the Thiessen-range (Thiessen polygon detailed in McGrady et al., 2002) in model c (see Section 3 for details).

a Variable $\log _{e}$ transformed.

b Variable arcsin square-root transformed.

c Measured as the average No. of $10 \mathrm{~m}$-contour lines crossed by two N-S and E-W transects of $1 \mathrm{~km}$ crossing each other over the centre of each $1 \mathrm{~km}^{2}$ quadrat contained within the $100 \mathrm{~km}^{2}$ quadrat. 
Table 4 - Performance of three logistic regression models discriminating between golden eagle territories and random locations (model details and equations in Table 3a-c)

\begin{tabular}{|c|c|c|c|c|c|c|}
\hline \multirow[t]{2}{*}{ Model based on } & \multicolumn{3}{|c|}{ 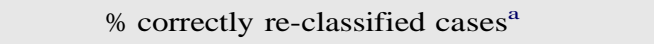 } & \multicolumn{3}{|c|}{$\%$ correctly classified cases $^{\mathrm{b}}$} \\
\hline & Eagle ranges & Random locations & Total & Eagle ranges & Random locations & Total \\
\hline a. Core-range & 79 & 76 & 77 & 90 & 80 & 85 \\
\hline b. Half-NND-range & 82 & 67 & 74 & 80 & 70 & 75 \\
\hline c. Thiessen-range & 91 & 94 & 92 & 90 & 100 & 95 \\
\hline
\end{tabular}

\section{6. $\quad$ Nest spacing and breeding success}

Three variables had access to a multiple regression with NND as the dependent variable: macro-ruggedness index, \% total grassland, and \% shrubs in evolution (Table 5a). Percentage total grassland was the only variable to enter a multiple regression with breeding success as the dependent variable (Table $5 b)$.

\subsection{Predictors of prey availability}

Three variables entered a stepwise multiple regression with Main prey availability as the dependent variable: \% total grassland, \% arid-rocky and \% shrubs in evolution (Table 5c).

\section{Discussion}

The logistic model based on the Thiessen-range performed consistently better than the other models, suggesting: (1) that it may have revealed the environmental factors of greater interest to the eagles, and (2) that the Thiessen-range may be a more realistic estimate of the actual range than a simple circle of fixed radius. The latter idea lends further support to the range-modelling technique originally devised by McGrady et al. (2002). Furthermore, given that the original range-estimate was based on telemetry data collected in Scotland in a profoundly different ecosystem, our results provide an independent test of the potential usefulness of such a modelling technique, further supporting the ongoing progressive refinements of the model by the Scottish team (e.g., McLeod et al., 2002a,b). On the other hand, our different range-models may reflect different components of habitat quality and all the variables included in all the final models converged towards factors such as territoriality, and availability of food and foraging habitats, which must be major determinants of eagle spatial choices. It may therefore be important to incorporate multiple range-estimates in habitat selection studies in order to increase the likelihood of detecting the relevant decision factors. Where such an approach is adopted, features that consistently appear in many alternative models should be paid extra-attention.

Compared to randomly located ranges, eagles selected ranges well-spaced out, characterised by a rugged topography and rich in main prey species and in open habitats favoured by their main prey species, such as grassland, shrubs, xerophytic vegetation and rocky outcrops. The selection for

Table 5 - Multiple regression models (GLM with normal errors and an identity link function) testing the effect of environmental variables on prey availability, nest spacing and productivity of a golden eagle population ( $\mathrm{n}=43$ territories) in the Trento region of the central-eastern Italian Alps

\begin{tabular}{|c|c|c|c|c|}
\hline Variable & B & $\mathrm{t}$ & $\mathrm{p}$ & $\mathrm{R}^{2}$ \\
\hline a. Effect on NND ${ }^{a}$ & & & & 0.57 \\
\hline Macro-ruggedness index ${ }^{\mathrm{b}}$ & $-0.07 \pm 0.03$ & -2.06 & $<0.05$ & \\
\hline$\%$ total grassland ${ }^{\mathrm{c}, \mathrm{d}}$ & $-0.58 \pm 0.23$ & 2.51 & $<0.05$ & \\
\hline$\%$ shrubs in evolution ${ }^{\mathrm{c}, \mathrm{e}}$ & $-1.11 \pm 0.35$ & 3.17 & $<0.005$ & \\
\hline Constant & $10.14 \pm 0.22$ & - & - & \\
\hline b. Effect on breeding success ${ }^{c}$ & & & & 0.24 \\
\hline$\%$ total grassland ${ }^{\mathrm{b}, \mathrm{c}}$ & $1.65 \pm 0.71$ & 2.33 & $<0.05$ & \\
\hline Constant & $0.21 \pm 0.29$ & - & - & \\
\hline c. Effect on Main prey species ${ }^{\mathrm{c}, \mathrm{d}}$ & & & & 0.61 \\
\hline$\%$ total grassland ${ }^{\mathrm{c}, \mathrm{d}}$ & $0.41 \pm 0.09$ & 4.42 & $<0.001$ & \\
\hline$\%$ arid-rocky ${ }^{\mathrm{c}, \mathrm{d}}$ & $0.21 \pm 0.06$ & 3.57 & $<0.01$ & \\
\hline$\%$ shrubs in evolution ${ }^{c, d}$ & $0.55 \pm 0.10$ & 5.31 & $<0.0001$ & \\
\hline Constant & $0.48 \pm 0.04$ & - & - & \\
\hline
\end{tabular}

a Variable $\log _{e}$ transtormed.

b Measured for the half-NND-range.

c Variable arcsin square-root transformed.

d Measured for the core-range.

e Measured for the Thiessen-range. 
overdispersion is a common feature of solitary, territorial raptors with a regular dispersion of nest-sites (e.g., Sergio et al., 2004a,b, 2005b). Such spacing behaviour may allow population density to be fine-tuned to resource availability, while simultaneously minimizing intraspecific competition (e.g., Newton, 1979; Village, 1983). Intraspecific fights have been identified as a major source of adult mortality and breeding failure for Alpine golden eagles (Haller, 1996). Furthermore, in our population, the estimated Thiessen-range size was higher for regularly dispersed territories than for randomly plotted locations (Table 2), suggesting that conspecific avoidance and a uniform distribution may lead to a more even share of available space. Along a similar line, the over-selection of sites with a rugged topography may imply a higher availability of three-dimensional space per unit of twodimensional space. It may also increase the potential for undetected approach to prey (Watson, 1991) and the number of ridges and slopes favouring the development of thermals and updrafts, which may facilitate foraging (McGrady et al., 2002; McLeod et al., 2002b). Such findings at the level of the individual may provide the mechanism behind the population-level relationship between topographical complexity and eagle population density previously reported for the Swiss Alps (Haller, 1996). Finally, the land-cover types over-selected by golden eagles in this study were all those which were also significant predictors of the abundance of main prey species, providing a link between prey distribution, foraging habitat availability and eagle choices. The fact that our direct estimate of prey availability entered only some of the models may imply that it was not a precise enough estimate of availability, or that landscape suitability for the eagles incorporated both prey abundance and the availability of open habitats structurally suitable for hunting. For example, a major prey species such as the roe deer is actually most abundant within woodland, but is usually captured by golden eagles when it ventures into open habitats (pers. obs.). It is also interesting that none of the single prey species variables entered a model, despite many of them being significant in univariate comparisons. This may not be so strange for a resident species with year-round, all-purpose territories and pronounced seasonal variations in diet composition (e.g., ungulate carrion in winter and live prey in spring-summer). Such species may prefer territories allowing year-round availability of all major prey, rather than focusing on one or two prey-types and their associated habitats in particular (see Southern and Lowe, 1968, for a similar argument). Overall, the tight relationship between golden eagle individuals or populations and food availability has been demonstrated in many previous studies (e.g., Watson et al., 1988, 1992; Jenny, 1992; Marzluff et al., 1997).

\subsection{Implications for conservation}

The extent of woodland habitats did not enter any of our models, suggesting that, at current levels, woodland may not be so detrimental for golden eagles. However, the expansion of woodland is mainly occurring at the expense of grassland, which on the contrary was a prey-rich, major determinant of eagle range selection, nest spacing and productivity. An even more subtle and dynamic threat is caused by the current selection by the eagles for shrub vegetation rapidly evolving into woodland. In the grassland ecosystems of the Alps, shrub encroachment usually takes place within 6-12 years of land abandonment (Laiolo et al., 2004), with a further 10-20 years before woodland develops. For golden eagles, the shrub stage probably implies an increase in prey availability, because shrubs bordering grassland are a good habitat for many of the eagle main prey species (e.g., Odasso et al., 2002). However, such habitat, which currently occupies on average almost $10 \%$ of the eagle ranges, will be ultimately lost to woodland, thus possibly functioning as an ecological trap. For some ranges, this will represent a woodland increase of more than $60 \%$ of its original extent. Finally, the uncertainty of the long-term effects of such losses is augmented by three further factors: (1) many of the eagle main prey species are currently increasing, mainly because of lower harvest rates by humans: for example, between 1980 and 2000, the local roe deer and alpine chamois populations increased by $158 \%$ and $253 \%$, respectively (Servizio Faunistico, 2001); (2) the effect of landscape changes on such prey species are also unknown; and (3) the recent, slow population increase of alpine golden eagles, probably associated with diminished persecution and higher prey supplies (Jenny, 1992; Haller, 1996), has been accompanied by a density-dependent decline in breeding output, again with unknown population consequences. Ultimately, golden eagle populations will depend on the complex interplay of density-dependence, pronounced habitat loss, and increases in prey abundance (but not necessarily availability). Given such complexity, and in view of the impossibility to develop firm predictions for the future, we propose that the most precautionary approach would be to halt the effects of land abandonment by strengthening subsidy schemes for traditional agro-pastoral practices. Such action would not only favour golden eagles but also (1) benefit a suite of other conservation-sensitive species (e.g., Laiolo et al., 2004), (2) counteract the progressive homogenisation of the Alpine landscape, and (3) preserve the cultural and historical value of an agropastoral system which dates back to 6000 years ago (Lichtenbergen, 1994).

\section{Acknowledgements}

We thank L. Licantropi, M. Moleón, A.S. Pullin and M. Wilson for comments on a previous draft of the manuscript. Part of this study was included in Project Biodiversità, funded by the Provincia Autonoma di Trento.

\section{R E F E R E N C E S}

Austin, G.E., Thomas, C.J., Houston, D.C., Thompson, B.A., 1996. Predicting the spatial distribution of buzzard Buteo buteo nesting areas using a Geographical Information System and remote sensing. J. Appl. Ecol. 33, 1541-1550.

Barbaro, L., Dutoit, T., Cozic, P., 2001. A six-year experimental restoration of biodiversity by shrub-clearing and grazing in calcareous grasslands of the French Alps. Biodivers. Conserv. 10, 119-135.

Brown, J.H., 1984. On the relationship between abundance and distribution of species. Am. Nat. 124, 255-279. 
Canals, R., Sebastià, M., 2000. Analyzing mechanisms regulating diversity in rangelands through comparative studies: a case in the southwestern Pyrenees. Biodivers. Conserv. 9, 965-984.

CEC. Commission of the European Communities,

Directorate-General - Environment, Nuclear Safety and Civil Protection, 1993. CORINE Land Cover - Guide technique. Office for Official Publications of the European Communities, Bruxelles.

Cernusca, A., Tappeiner, U., Bayfield, N., 1999. Land-use changes in European mountain ecosystems. Blackwell Wissenschafts-Verlag, Berlin.

CIPRA, 2001. Report on the status of the Alps 2: data, facts, problems, proposals. Centro Documentazione Alpina, Torino.

Crawley, M.J., 1993. GLIM for Ecologists. Blackwell Science, Oxford.

Dirnböck, T., Dullinger, S., Grabherr, G., 2003. A regional impact assessment of climate and land-use change on alpine vegetation. J. Biogeog. 30, 401-407.

Fielding, A.H., Bell, J.F., 1997. A review of methods for the assessment of prediction errors in conservation presence/ absence models. Environ. Conserv. 24, 38-49.

Forman, R.T.T., 1995. Land Mosaics: The Ecology of Landscapes and Regions. Cambridge University Press, Cambridge.

Green, R.H., 1979. Sampling Design and Statistical Methods for

Environmental Biologists. John Wiley and Sons, New York. Haller,

H., 1982. Raumorganisation und dynamik einer population des Steinadlers Aquila chrysaetos in den zentralalpen. Orn. Beob. 79, 163-211.

Haller, H., 1996. Der Steinadler in Graubünden. Langfristige Untersuchungen zur Populationsökologie von Aquila chrysaetos im Zentrum der Alpen. Orn. Beob. 9, 1-167.

Haller, H., Sackl, P., 1997. Golden eagle Aquila chrysaetos. In: Hagemeijer, W.J.M., Blair, M.J. (Eds.), The EBCC Atlas of European Breeding Birds their Distribution and Abundance. T and AD Poyser, London, pp. 170-171.

Hanski, I., 1999. Metapopulation Ecology. Oxford University Press, Oxford.

Holtmeier, F.K., 1994. Ecological aspects of climatically-caused timberline fluctuations: review and outlook. In: Beninston, $\mathrm{M}$. (Ed.), Mountain Environments in Changing Climates. Routledge, London, pp. 220-233.

Hooge, P.N., Eichenlaub, B., 1997. MovementAnimal Movement Extension to ArcView ver. 1.1. Alaska Biological Science Center, US Geological Survey, Anchorage.

Hunter, M.L. (Ed.), 1999. Maintaining Biodiversity in Forest Ecosystems. Cambridge University Press, Cambridge.

Hutchings, M.J., John, E.A., Stewart, A.J.A. (Eds.), 2000. The Ecological Consequences of Environmental Heterogeneity. Blackwell Science, Oxford.

Jenny, D., 1992. Bruterfolg und Bestandsregulation einer alpinen Population des Steinadlers Aquila chrysaetos. Orn. Beob. 89, $1-43$.

Kochert, M.N., Steenhof, K., Carpenter, L.B., Marzluff, J.M., 1999. Effects of fire on Golden Eagle territory occupancy and reproductive success. J. Wildl. Manage. 63, 773-780.

Krebs, C.J., 1998. Ecological Methodology. HarperCollins, New York.

Laiolo, P., Dondero, F., Ciliento, E., Rolando, A., 2004.

Consequences of pastoral abandonment for the structure and diversity of the alpine avifauna. J. Appl. Ecol. 41, 294-304.

Lichtenbergen, E., 1994. Die Alpen in Europa. Osterreichische Akademie der Wissenschften. Verö ff. Komm. Humanökologie 5, 53-86.

Marquiss, M., Ratcliffe, D.A., Roxburgh, R., 1985. The numbers, breeding success and diet of Golden eagles in southern Scotland in relation to changes in land use. Biol. Conserv. 34, 121-140.

Marzluff, J.M., Knick, S.T., Vekasy, M.S., Schueck, L.S., Zarriello, T.J., 1997. Spatial use and habitat selection of Golden Eagles in southwestern Idaho. Auk 114, 673-687.
McGrady, M.J., 1997. Aquila chrysaetos Golden Eagle. BWP Update 1, 99-114.

McGrady, M.J., Grant, J.R., Bainbridge, I.P., McLeod, D.R.A., 2002. A model of Golden Eagle (Aquila chrysaetos) ranging behavior. J. Raptor Res. 36, 62-69.

McLeod, D.R.A., Whitfield, D.P., McGrady, M.J., 2002a. Improving prediction of Golden Eagle (Aquila chrysaetos) ranging in western Scotland using GIS and terrain modeling. J. Raptor Res. 36, 70-77.

McLeod, D.R.A., Whitfield, D.P., Fielding, A.H., Haworth, P.F., McGrady, M.J., 2002b. Predicting home range use by Golden eagles Aquila chrysaetos in western Scotland. Avian Sci. 2, 183-198.

Newton, I., 1979. Population Ecology of Raptors. T and A D Poyser, Berkhamsted.

Niemelä, J., Baur, B., 1998. Threatened species in a vanishing habitat: plants and invertebrates in calcareous grasslands in the Swiss Jura Mountains. Biodivers. Conserv. 7, $1407-1416$.

Odasso, M., Mayr, S., De Francesci, P.F., Zorzi, S., Mattedi, S., 2002. Miglioramenti Ambianetali a fini faunistici: localizzazione delle zone, priorità e modalità gestionali per interventi a favore di Lepre comune, Fagiano di monte, Coturnice e Re di quaglie. Provincia Autonoma di Trento, Trento.

Pain, D.J., Pienkowski, M.W. (Eds.), 1997. Farming and Birds in Europe: The Common Agricultural Policy and its Implications for Bird Conservation. Academic Press, London.

PAT, 1995. Rapporto sullo stato dell'ambiente. Provincia Autonoma di Trento, Trento.

Pedrini, P., Sergio, F., 2001a. Golden eagle Aquila chrysaetos density and productivity in relation to land abandonment and forest expansion in the Alps. Bird Study 48, 194-199.

Pedrini, P., Sergio, F., 2001b. Density, productivity, diet, and human persecution of Golden eagles (Aquila chrysaetos) in the centraleastern Italian Alps. J. Raptor Res. 35, 40-48.

Pedrini, P., Sergio, F., 2002. Regional conservation priorities for a large predator: golden eagles (Aquila chrysaetos) in the Alpine range. Biol. Conserv. 103, 163-172.

Penteriani, V., Gallardo, M., Roche, P., 2002. Landscape structure and food supply affect eagle owl (Bubo bubo) density and breeding performance: a case of intra-population heterogeneity. J. Zool. 257, 365-372.

Piussi, P., 1992. Carta del limite potenziale del bosco in Trentino. Provincia Autonoma di Trento, Servizio Foreste, Caccia e Pesca, Trento.

Rice, W.R., 1989. Analyzing tables of statistical tests. Evolution 43, 223-225.

Sergio, F., Bogliani, G., 2000. Hobby Falco subbuteo nest-site selection and productivity in relation to intensive agriculture and forestry. J. Wildl. Manage. 64, 637-646.

Sergio, F., Pedrini, P., Marchesi, L., 2003a. Spatio-temporal shifts in gradients of habitat quality for an opportunist avian predator. Ecography 26, 243-255.

Sergio, F., Pedrini, P., Marchesi, L., 2003b. Adaptive selection of foraging and nesting habitat by black kites (Milvus migrans) and its implications for conservation: a multi-scale approach. Biol. Conserv. 112, 351-362.

Sergio, F., Marchesi, L., Pedrini, P., 2004a. Integrating individual habitat choices and regional distribution of a biodiversity indicator and top predator. J. Biogeog. 31, 619-628.

Sergio, F., Rizzolli, F., Marchesi, L., Pedrini, P., 2004b. The importance of interspecific interactions for breeding-site selection: Peregrine Falcons seek proximity to Raven nests. Ecography 27, 818-826.

Sergio, F., Blas, J., Forero, M., Donázar, J.A., Hiraldo, F., 2005a. Preservation of wide-ranging top predators by site-protection: black and red kites in Doñana National Park. Biol. Conserv. $125,11-21$. 
Sergio, F., Scandolara, C., Marchesi, L., Pedrini, P., Penteriani, V., 2005b. Effect of agro-forestry and landscape changes on common buzzards (Buteo buteo) in the Alps: implications for conservation. Animal Conserv. 7, 17-25.

Servizio Faunistico, 2001. Analisi delle consistenze e dei prelievi di ungulati e tetraonidi in provincia di Trento. Provincia Autonoma di Trento, Trento.

Servizio Foreste, 1999. Carta fisionomica della copertura forestale in Trentino. Provincia Autonoma di Trento, Trento.

Sokal, R.R., Rohlf, F.J., 1981. Biometry. W.H. Freeman, New York.

Southern, H.N., Lowe, V.P.W., 1968. The pattern of distribution of prey and predation in Tawny owl territories. J. Anim. Ecol. 37, 75-97.

Steenhof, K., Kochert, M.N., Doremus, J.H., 1983. Nesting of subadult Golden Eagles in southwestern Idaho. Auk 100, 743-747.

Tabachnick, B.G., Fidell, L.S., 1996. Using Multivariate Statistics. HarperCollins, New York.

Tucker, G.M., Evans, M.I. (Eds.), 1997. Habitats for Birds in Europe: A Conservation Strategy for the Wider Environment. BirdLife International, Cambridge.

Village, A., 1983. The role of nest-site availability and territorial behaviour in limiting the breeding density of Kestrels. J. Anim. Ecol. 52, 635-645.
Watson, J., 1991. The Golden Eagle and pastoralism across Europe. In: Curtis, D.J., Bignal, E.M., Curtis, M.A. (Eds.), Birds and Pastoral Agriculture in Europe. JNCC, Peterborough, pp. 56-57.

Watson, J., 1992. Golden Eagle Aquila chrysaetos breeding success and afforestation in Argyll. Bird Study 39, 203-206.

Watson, J., 1994. Golden eagle Aquila chrysaetos. In: Tucker, G.M., Heath, M.F. (Eds.), Birds in Europe: Their Conservation Status. BirdLife International, Cambridge, pp. 181-182.

Watson, J., 1997. The Golden Eagle. T and AD Poyser, London.

Watson, J., Whitfield, P., 2002. A conservation framework for the Golden Eagle (Aquila chrysaetos) in Scotland. J. Raptor Res. 36, 41-49.

Watson, A., Payne, S., Rae, R., 1988. Golden Eagles Aquila chrysaetos: land use and food in northeast Scotland. Ibis 131, 336-348.

Watson, J., Rae, S.R., Stillman, R., 1992. Nesting density and breeding success of golden eagles in relation to food supply in Scotland. J. Anim. Ecol. 61, 543-550.

Whitfield, D.P., McLeod, D.R.A., Fielding, A.H., Broad, R.A., Evans, R.J., Haworth, P.F., 2001. The effect of forestry on golden eagles on the island of Mull, western Scotland. J. Appl. Ecol. 38, $1208-1220$.

Zar, J.H., 1984. Biostatistical Analysis. Prentice-Hall International Editions, Englewood Cliffs. 